\title{
Questão Ambiental: dimensão periférica em política pública de turismo ${ }^{1}$
}

\author{
Cynthia Oliveira de Souzaa \\ Magnus Luiz Emmendoerfer ${ }^{b}$ \\ Marcos Eduardo Carvalho Gonçalves Knupp ${ }^{c}$
}

\section{Resumo}

No século XX, o turismo foi objeto de atenção em políticas públicas de governos centrais de diferentes países. No século XXI, devido ao processo de descentralização, o turismo passou a ser também um setor de interesse de governos subnacionais em prol do desenvolvimento local e regional. 0 objetivo deste artigo é analisar a questão ambiental na política pública de turismo planejada por um governo subnacional em um estado federativo. Para tanto, foram aplicados o método documental cujos dados coletados foram cotejados a luz da literatura especializada. Como resultados, identificou-se as prioridades e as questões consideradas importantes por um governo em uma política pública de turismo a partir de um esquema analítico de 15 tipos de objetivos e 22 formas de atuação governamental. Na situação analisada, observou-se que a questão ambiental não é algo central na política vigente, o que pode tornar preocupante a sustentabilidade do turismo para além da dimensão econômica. Por fim, o esquema analítico empregado possibilita compreender a intencionalidade e a abrangência de uma política pública de turismo.

Palavras-chave: Desenvolvimento turístico; Federalismo; Gestão pública; São Paulo; Brasil.

\section{Abstract}

\section{Environmental Issue: Peripheral Dimension in a Tourism Policy?}

In the twentieth century, tourism was the object of attention in public policies of central governments in different countries. In the 21st century, due to the decentralization process, tourism has also become a sector of interest for subnational governments in favor of local and regional development. The objective of this article is to analyze the environmental issue in the tourism policy planned by a subnational government in a federated state. For this, documentary method was applied, whose collected data were compared in light of specialized literature. As a result, the priorities and issues considered important by government in a tourism policy were identified based on an

1. Trabalho contou com fomento do Conselho Nacional de Desenvolvimento Científico e Tecnológico - CNPq e da Fundação de Amparo à Pesquisa do Estado de Minas Gerais - FAPEMIG e recebeu contribuições dos membros do comitê científico do Seminário Mineiro de Pesquisa e Inovação em Turismo realizado em 2016 em Belo Horizonte, Minas Gerais, Brasilpelas.

a. Bacharela em Cooperativismo pela Universidade Federal de Viçosa (UFV), Viçosa, Minas Gerais, Brasil. E-mail: cynthiacooperativismo@gmail.com

b. Pós-doutor em Ciências da Administração (Concentração em Administração Pública) pela Universidade do Minho e Pós-doutore em Turismo na Universidade do Algarve, Portugal. Docente da Universidade Federal de Viçosa (UFV), Viçosa, Minas Gerais, Brasil. E-mail: magnus.emmendoerfer@ gmail.com

c. Pós-doutor em Administração Universidade Federal de Viçosa (UFV), Pós-doutor em Ciência Política pela Universidad Complutense de Madrid. Docente da Universidade Federal de Ouro Preto (UFOP). E-mail: marcos.knupp@gmail.com 
analytical framework of 15 types of objectives and 22 forms of governmental action. In the analyzed situation, it was observed that the environmental issue is not something central in the current policy, which can cause concern for the sustainability of tourism beyond the economic dimension. Finally, the analytical framework employed makes it possible to understand the intentionality and comprehensiveness of a tourism policy.

Keywords: Touristic development; Federalism; Public Management; São Paulo; Brazil.

\section{Resumen}

\section{Cuestión Ambiental: ¿Dimensión Periférica en Política Pública de Turismo?}

En el siglo XX, el turismo fue objeto de atención en políticas públicas de gobiernos centrales de diferentes países. En el siglo XXI, debido al proceso de descentralización, el turismo pasó a ser también un sector de interés de gobiernos subnacionales a favor del desarrollo local y regional. El objetivo de este artículo es analizar la cuestión ambiental en la política pública de turismo planeada por un gobierno subnacional en un Estado federativo. Para eso, fue aplicado el método documental cuyos datos colectados fueron cotejados a la luz de la literatura especializada. Como resultados, se identificó las prioridades y las cuestiones consideradas importantes por un gobierno en una política pública de turismo a partir de un esquema analítico de 15 tipos de objetivos y de 22 formas de actuación gubernamental. En la situación analizada, se observó que la cuestión ambiental no es algo central en la política vigente, lo que puede volver preocupante la sustentabilidad del turismo más allá de la dimensión económica. Por fin, el esquema analítico aplicado posibilita comprender la intencionalidad y la amplitud de una política pública de turismo.

Palabras clave: Desarrollo turístico; Federalismo; Gestión pública; São Paulo; Brasil.

\section{INTRODUÇÃo}

O turismo nas últimas décadas tem se destacado enquanto atividade produtiva e tem gradualmente se tornado objeto de interesse em vários países do mundo. A atividade turística pode trazer diversos benefícios (e riscos) a partir do crescimento econômico que pode ser observado em determinados países com base em estudos da Organização Mundial do Turismo (OMT, 2003).

Dwyer e Spurr (2012) mencionam que os governos estão cada vez mais atentos às oportunidades de geração de renda e de crescimento do emprego resultantes do turismo, o que auxilia compreender os esforços estatais em propagar a imagem dos destinos, em círculos amplos e reduzidos, em termos políticos e geográficos, públicos e privados, e isso incentivaria o desenvolvimento socioeconômico em continentes, países, regiões e municípios (JAFARI, 1994).

Beni (2003), Bezerra (2003) e Guedes (2003) compartilham a noção de turismo como sendo uma atividade de múltiplos serviços com abrangência intersetorial e capacidade de ser flexível às mudanças e demandas da humanidade, tanto no tempo quanto no espaço. No entanto, Ruschmann (2010) e Oliveira, Minasse e Marques (2016) mencionam que devido ao seu crescimento, muitas vezes não planejado e sem monitoramento, o turismo pode impactar negativamente as localidades, acarretando à necessidade de pensá-lo, não só como uma atividade 
que promove o crescimento econômico, mas também como uma atividade multidimensional de desenvolvimento.

Neste sentido, os impactos ambientais do turismo não se vinculam somente à sua realização, mas também a sua implementação no que se refere a sua infraestrutura, a população local e a cultura dos turistas que vão para os destinos (Feitosa \& Gómez, 2013). Para as autoras, se não bem planejados, os elementos que compõem a infraestrutura turística, tais como os serviços de transporte, hotelaria, alimentação e até mesmo serviços de abastecimento de água e energia, podem contribuir para a geração de impactos ambientais.

0 turismo tem uma considerável dependência do ambiente natural para seu desenvolvimento (Feitosa \& Gómez, 2013) e é por isso que se torna necessário desenvolver o turismo de maneira sustentável através da formulação de políticas que contemplem a multiplicidade de forças que interferem na atividade turística (Goldneret al., 2002), principalmente no que tange à questão ambiental.

No entanto, para que se aconteça o turismo de forma sustentável, todas as partes envolvidas no processo de planejamento precisam se comprometer com os princípios do desenvolvimento sustentável para que se alcance a integração dos objetivos sociais, ambientais e econômicas do turismo no longo prazo (Hall, 2000).

A partir disso, observa-se que os bens naturais, culturais e sociais das localidades, materializados e imateriais, passam a ser cada vez mais objeto de valor e de interesse coletivo a serem contemplados no planejamento das ações turísticas. E isso passa exigir a atuação mais próxima e eficiente do Estado, por meio dos governos, no planejamento das atividades turísticas, uma vez que são as localidades com os seus residentes são os principais afetados pelos êxitos e danos de sua prática. Mas, como isso ocorre em países federais ou federativos? Será que a questão ambiental é um objetivo prioritário em políticas públicas de turismo?

Essas inquietudes trazem à tona o debate do Federalismo e da atuação dos governos em relação ao turismo como instrumento de desenvolvimento. No mundo, segundo do Fórum das Federações (2016) existem 26 países que possuem o federalismo como um sistema político interno. Segundo Young (2015), este sistema serve de orientação para os governos (nacional e subnacionais) exercerem os seus poderes sobre a sociedade, por meio da congregação da diversidade de unidades territoriais menores em um território maior, dotado de soberania reconhecida internacionalmente para o alcance do bem comum por meio de políticas públicas.

A discussão sobre o Federalismo no contexto de políticas públicas de turismo e do desenvolvimento turístico pode auxiliar na compreensão dos elementos que os gestores públicos em países organizados sob a forma de uma federação lidam e priorizam em suas escolhas em políticas de desenvolvimento, tanto no governo central ou federal, quanto nos demais entes estaduais e/ou municipais, em seus respectivos governos subnacionais.

Ao considerar o federalismo e as políticas públicas nos estudos sobre turismo, possibilita-se observar o protagonismo e as escolhas de governos subnacionais, a fim de se compreender as prioridades e abrangência, bem como os temas de interesse acerca do turismo como instrumento de desenvolvimento territorial (Alvarez \& Cooper, 2014; Airey, 2015). Isso possibilita trazer novos conhecimentos e insights para a gestão e políticas públicas de turismo em níveis regional e mu- 
nicipal, deslocando o eixo da centralidade das atenções de políticas de governos nacionais, para os de governos subnacionais de modo singular ou em perspectiva comparada.

Neste sentido, o princípio da autonomia, destacado por Rua e Romanini (2013), dota as unidades subnacionais de um país, ou seja, os estados de uma República Federativa, de autonomia necessária para tomar decisões e resolver determinados problemas públicos, como a geração de valores e de impactos provenientes das práticas do turismo.Assim, políticas públicas de turismo podem ser exemplos de ações de entidades federativas que possibilitam o desenvolvimento, tanto econômico quanto social e cultural, de determinadas localidades, dando a estas a oportunidade de desenvolverem seus potenciais turísticos de forma ordenada, além de darem acesso a geração de emprego e renda à população. Neste sentido, como a questão ambiental se apresenta nos objetivos e nas formas de atuação de governo subnacional em prol do desenvolvimento turístico?

Pergunta semelhante a supramencionada serviu de orientação para o estudo de Scott (2011) que ao analisar as políticas públicas de turismo em diversos países identificou diferentes objetivos e formas de atuação governamental. Entretanto, o estudo de Scott (2011) concentrou-se em políticas nacionais de turismo, sem levar em consideração os governos subnacionais e a centralidade da questão ambiental em políticas públicas, objeto de interesse neste artigo.

A questão norteadora deste artigo é importante porque ao conhecer os objetivos, as prioridades e a abrangência das ações governamentais contempladas em uma política pública de turismo permite-se compreender como esta atividade setorial em relação a questão ambiental pode possibilitar o desenvolvimento local e regional, bem como fortalecer e ampliar os estudos da temática de políticas públicas de turismo, sob uma abordagem multidisciplinar. Isso pode possibilitar minimizar a incipiência ainda latente nos estudos e análises sobre "políticas públicas nos periódicos especializados em turismo no Brasil" (Lopes, Tinôco, Souza, 2011, p. 628), buscando afinação com a análise de políticas públicas (planos, programas e projetos) do setor turístico dos diversos níveis de atuação - federal, estadual e municipal.

\section{IMPACTOS DO TURISMO E A QUESTÃO AMBIENTAL COMO OBJETO DE POLÍTICAS PÚBLICAS}

O turismo é uma atividade de grande impacto socioeconômico e afeta, consideravelmente, a dinâmica da sociedade e das organizações, fazendo com que os governos criem normas jurídico-legais para minimizar riscos nas transações que aí tem lugar. Entretanto, estes instrumentos normativos produzem efeitos distributivos diversos, inclusive ambiental, alocando desigualmente os custos e os benefícios entre segmentos e organizações que operam no setor, tornando possível a compreensão das tensões e dos limites para a atuação do poder público que aí se estabelecem.

A natureza multidisciplinar do turismo é importante "para formular políticas que deem conta ou abordem essas múltiplas forças, os envolvidos devem considerar as complexidades de cada disciplina e suas interações numa dada situação" (Goeldneret al., 2002, p.298). Os múltiplos impactos da atividade turística 
na sociedade, por meio de três tipos de efeitos - diretos, indiretos e induzidos -, evidenciam a sensibilidade que a política pública de turismo deve ter. Portanto, a interdisciplinaridade se afigura como mais um requerimento das políticas públicas, elemento imprescindível para se tratar a questão ambiental na perspectiva do desenvolvimento do turismo.

Levando em consideração que a literatura especializada em turismo valoriza a importância do desenvolvimento sustentável da atividade, não se pode esquecer que o conceito de sustentabilidade tem uma dimensão econômica ao lado de suas dimensões social e ambiental (Dwyer\&Spurr, 2012).Este tipo de aplicação para o estudo do turismo está relacionadoao fato de que:

[...] para reduzir a pobreza, melhorar a igualdade e gerar empregos o crescimento econômico precisa ser inclusivo, voltado para o desenvolvimento sustentável, a fim de resguardar recursos presentes para as futuras gerações, e a atividade turística já demonstrou, em algumas regiões, que possui potencial para isso. A OMT tem um papel importante como difusora desta abordagem, pois promove programas e projetos a fim de introduzir estudos e práticas voltadas ao turismo sustentável em algumas regiões consideradas subdesenvolvidas (Knupp, 2015, p.34).

0 requerimento de sustentabilidade no turismo significa que as políticas neste setor necessitam assegurar relações de consumo no presente não afetem as possibilidades de consumo futuro. No cerne deste conceito está a questão ambiental que se tornou o centro de diversas discussões num mundo marcado com a busca incessante pelo desenvolvimento, e o fenômeno turismo, tratado como uma atividade que pode trazer desenvolvimento para diversas regiões, também entra em pauta nesta discussão.

A década de 1970 foi palco de diversos encontros marcantes entre especialistas para a discussão sobre a questão ambiental. A preocupação com o meio ambiente fez surgir conferências que marcaram épocas e redesenharam um perfil dentro da comunidade global, as pessoas que se preocupam e discutem sobre a preservação do meio ambiente. Dessa forma, surge o conceito de desenvolvimento sustentável que vem como contraposição ao crescimento desordenado da população mundial.

Nesse âmbito, em 1972 dois eventos delimitaram correntes - o Clube de Roma e a Conferência de Estocolmo. A diferença é que o trabalho do Clube de Roma segue a ideia do congelamento do crescimento da população global e do capital industrial, onde foram mostrados os limites dos recursos para a quantidade de pessoas, já a Conferência de Estocolmo vem com uma crítica ambiental em relação ao modo de vida contemporâneo, apresentando uma abordagem da educação para o meio ambiente; mas os dois demonstraram um propósito em comum que é a necessidade de tornar compatível a qualidade de vida da população com a preservação ambiental.

Outros eventos considerados importantes são a Conferência Internacional e a publicação do Relatório de Brutland, os dois aconteceram em 1987. 0 primeiro também foi promovido pela UNESCO e PNUMA que tem como foco a educação ambiental, fazendo balanço dos avanços e propondo estratégias futuras em âmbito internacional. 0 relatório foi elaborado pela Comissão das Nações Unidas sobre Meio Ambiente e Desenvolvimento (CNUMAD), criada pela ONU, que de- 
fende o desenvolvimento sustentável e novamente é destacada a importância da educação ambiental.

Mais adiante, em 1992 aconteceu na Rio 92 o Tratado de Educação Ambiental para Sociedades Sustentáveis e Responsabilidade Global, onde são expostos princípios e um plano de ação para educadores ambientais, estabelecendo uma relação entre as políticas públicas de educação ambiental e a sustentabilidade que tem sido usado como uma referência para ações políticas e estudos teóricos (Lima, 1999; Jacobi, 2003), inclusive no campo do turismo.

Segundo Torres-Delgado e Palomeque (2014), a relação entre turismo e sustentabilidade sempre existiu, mas só foi reconhecido mais tarde quando o paradigma do turismo sustentável foi definido pelas instituições oficiais, sobre o foco da dimensão ambiental. Neste sentido, o conceito de turismo sustentável apareceu em estreita ligação com a noção de desenvolvimento sustentável, assim, abordou as novas necessidades do setor de turismo dentro de um contexto socioeconômico em mudança, chamando atenção para um novo modelo (Torres-Delgado \& Palomeque, 2014).

Para que ocorra o turismo sustentável, todas as partes envolvidas no processo de planejamento precisam estar comprometidas com os princípios do desenvolvimento sustentável, somente assim se pode alcançar a integração de objetivos sociais, ambientais e econômicos, bem como culturais e políticos, a longo prazo (Hall, 2000).

No entanto, há que se chamar a atenção, "embora seja reconhecido que os princípios para o turismo sustentável são, de fato, um ponto de partida adequado, a natureza vaga das orientações faz pouco para incentivar o entusiasmo ou a compreensão do desenvolvimento do turismo sustentável" (Berry \& Lakedin, 1997, p.435).

Podemos considerar a sustentabilidade como elemento significativo na mensuração do desempenho turístico, ou seja, como um dos parâmetros de análise existentes e no consequente aperfeiçoamento da atividade turística, o que perpassa também pela necessidade de incorporação de tais inovações na formulação e implementação das políticas públicas de turismo. Portanto, o turismo é um campo que se relaciona diretamente com a questão ambiental, pois a compreensão que temos, atualmente, é que devemos trabalhar a atividade turística sobre os moldes do turismo sustentável, ou seja, não enquanto um segmento do turismo, mas enquanto uma linha de desenvolvimento geral de toda atividade.

\section{POLÍTICAS PÚBLICAS DE TURISMO E DESENVOLVIMENTO TURÍSTICO}

Em uma República Federativa, como no caso do Brasil, sua organização política-administrativa se dá através de três entidades federativas: a União, os Estados e os Municípios. Nesse sistema, todos as três entidades são dotadas de autonomia, o que as fazem constituir um sistema político completo. Ao tratar desse tema, Rua e Romanini (2013), destacam dois grandes princípios que integram essa forma de Estado, sendo estes o princípio da autonomia e o princípio da participação. Ao enfatizar o princípio da autonomia pode-se ver que este, segundo 
as autoras, se apresenta por meio de uma capacidade trina dos estados-membros de se:

- Auto organizarem: No que diz respeito ao exercício de seu poder constituinte e ao seu direito de elaborar suas Constituições Estaduais, respeitando sempre a Constituição Federal;

- Auto governarem: Está ligado à eleição de seus representantes estaduais por meio de votação direta;

- Auto administrarem: Se relaciona com a determinação de atividades administrativas, legislativas e tributárias.

A partir disso, verifica-se que as unidades subnacionais de Estados Federativos são sistemas políticos autônomos e completos, ou seja, possuem os três poderes: Executivo, Legislativo e Judiciário, o que lhes permitem a tomada de decisão e a resolução de problemas públicos existentes dentro de seus devidos territórios, sendo estas ações por meio das políticas públicas.

Neste sentido, a política pública pode ser "[...] uma diretriz elaborada para enfrentar [este problema, o qual] deve ter implicações para uma quantidade ou qualidade notável de pessoas" (Secchi, 2013, p.10). Diante disso, observa-se que a política pública é uma das maneiras de o Estado resolver, ou ao menos amenizar, problemas que atinjam um grande número de pessoas.

Secchi (2013) ainda contribui dizendo que a vida de uma política pública pode ser resumida em sete fases, embora muitas políticas não sigam à ordem das fases ou nem cheguem a completá-las. Isso acontece pelo fato do ciclo de políticas públicas infrequentemente refletir a real atividade, vida e dinâmica de uma política pública. As setes fases do ciclo de vida das políticas públicas são: 1. Identificação do problema; 2. Formação da agenda; 3. Formulação de alternativas; 4. Tomada de decisão; 5. Implementação; 6. Avaliação; 7. Extinção.

As políticas públicas no Brasil têm sido organizadas e elaboradas de modo descentralizado, em que suas ações e obrigações se diferem entre as três entidades federativas, resultando na possibilidade dos Estados formularem suas próprias políticas públicas a fim de que regiões que mais precisem, ou que tenham maior potencial, sejam beneficiadas e se desenvolvam (Henz \& Anjos, 2014).

Isso porque em países de grande extensão territorial existe uma maior complexidade ao realizar o gerenciamento do território nacional, principalmente no âmbito do turismo (Solha, 2004). Para esta autora, criam-se estruturas administrativas intermediárias para fins de implementação e monitoramento de ações e políticas, uma vez que estão mais próximas do cotidiano dos setores que sofrerão as intervenções. Heinz e Anjos (2014) corroboram com o argumento apresentado ao afirmarem que com a descentralização, as funções administrativas acabam sendo distribuídas entre os níveis de governo, fazendo com que haja a transferência de recursos e delegação de funções entre as unidades federativas e municípios, aumentando assim o grau de autonomia destes em relação a própria federação.

No âmbito do turismo e com base na política de turismo nacional, expressa na lei 11.771/2008, Pimentel, Pimentel e Vidal (2017) alegam que o Brasil, através do governo federal, pretende estimular o ordenamento do turismo no país por meio do exercício de seu poder pelos próprios estados e municípios, estimulando assim a articulação entre eles. 
As políticas públicas de turismo são uma forma de promoção de desenvolvimento local e regional e podem ser tratadas, coadunando com Carvalho (2000), como um conjunto de decisões relativas a destinação de valores que se encontram unidas e amparadas legalmente em programas, projetos, planos e demais ações do Estado em suas três entidades federativas: União, Estados e Municípios, no que se refere ao turismo. Para Henz e Anjos (2014, p. 14), as políticas públicas de turismo visam:

[...] o planejamento e o controle da atividade para que haja total aproveitamento dos recursos turísticos administrados de maneira a atrair o maior número possível de visitantes, beneficiando tanto os agentes e intermediários, quanto turistas e os próprios residentes, buscando acima de tudo o equilíbrio e a sustentabilidade.

Uma vez que, em sua maioria, são criadas para fomentar a atividade turística nas regiões do país que possuem potenciais ou atividades turísticas já estabelecidas, as políticas públicas de turismo possibilitam essas regiões se desenvolverem e de dinamizarem suas atividades, além de buscar incrementar a qualidade de vida das pessoas que dependem de tais atividades no que diz respeito a geração de emprego e renda (Emmendoerfer, Tomazzoni, Pimentel, 2014).

Scott (2011), buscou identificar os principais objetivos das políticas públicas de turismo e a atuação dos governos em diversas partes do mundo. Através de seu estudo, o autor pode identificar 15 objetivos e 22 atuações, conforme visualizadas na Tabela 1:

Quadro 1 - Objetivos das Políticas Públicas de Turismo e Formas de Atuação Governamental

\begin{tabular}{|c|c|}
\hline $\begin{array}{l}\text { Objetivos das Políticas } \\
\text { Públicas de Turismo }\end{array}$ & Formas de Atuação Governamental \\
\hline \multirow[t]{3}{*}{$\begin{array}{l}\text { 1. Desenvolvimento } \\
\text { Econômico }\end{array}$} & $\begin{array}{l}\text { 1. Pesquisa e divulgação de informações sobre tendências } \\
\text { futuras do mercado }\end{array}$ \\
\hline & 2. Fortalecimento da imagem do destino \\
\hline & $\begin{array}{l}\text { 3. Garantir acesso efetivo ao mercado e prestação de consultoria } \\
\text { e apoio aos negócios }\end{array}$ \\
\hline 2. Competitividade & $\begin{array}{l}\text { 4. Sistemas de qualidade e de classificação obrigatórios } \\
\text { poderiam tornar-se voluntários e ser colocados nas mãos do } \\
\text { setor privado ou terceiro setor }\end{array}$ \\
\hline \multirow[t]{2}{*}{ 3. Prosperidade Local } & 5. Criação de empregos em turismo \\
\hline & 6. Contribuição para o desenvolvimento de infraestrutura \\
\hline 4. Qualidade de emprego & $\begin{array}{l}\text { 7. Fortalecer as atividades que garantem empregos de tempo } \\
\text { inteiro e durante todo o ano, para incentivar a formação e } \\
\text { oportunidades de progressão na carreira }\end{array}$ \\
\hline \multirow[t]{3}{*}{ 5. Equidade social } & $\begin{array}{l}\text { 8. Canalizar gastos e renda para as pessoas desfavorecidas e os } \\
\text { pobres }\end{array}$ \\
\hline & $\begin{array}{l}\text { 9. Ajudar os pobres a participarem da oferta turística e apoiar a } \\
\text { constituição de empresas dentro de comunidades pobres }\end{array}$ \\
\hline & 10. Estímulo ao turismo social \\
\hline
\end{tabular}

(continua...) 
Quadro 1 - Continuação

\begin{tabular}{|c|c|}
\hline $\begin{array}{l}\text { Objetivos das Políticas } \\
\text { Públicas de Turismo }\end{array}$ & Formas de Atuação Governamental \\
\hline \multirow[t]{2}{*}{$\begin{array}{l}\text { 6. Atendimento ao } \\
\text { visitante }\end{array}$} & $\begin{array}{l}\text { 11. Proporcionar às pessoas, incluindo a população nacional, } \\
\text { uma experiência de viagem de qualidade, lúdica e educativa }\end{array}$ \\
\hline & $\begin{array}{l}\text { 12. Promover o turismo como um fim em si mesmo, isto é, um } \\
\text { direito disponível futuro do turismo em sua área, consultando } \\
\text { outras partes interessadas }\end{array}$ \\
\hline 7. Controle local & $\begin{array}{l}\text { 13. Garantir boa informação e empoderamento para tomar } \\
\text { decisões sobre o desenvolvimento do turismo que possa afetar } \\
\text { seu futuro }\end{array}$ \\
\hline $\begin{array}{l}\text { 8. Bem-estar da } \\
\text { comunidade }\end{array}$ & $\begin{array}{l}\text { 14. Realizar um planejamento cuidadoso para garantir que } \\
\text { a comunidade local não sofra com o turismo, como através } \\
\text { do congestionamento do tráfego, barulho, comportamento } \\
\text { desrespeitoso, e competição por recursos vitais, como a água }\end{array}$ \\
\hline 9. Riqueza cultural & $\begin{array}{l}\text { 15. Apoiar a conservação da cultura; os sítios de patrimônio e } \\
\text { tradições históricos, controlando o desenvolvimento do turismo } \\
\text { e o comportamento do visitante para garantir que a riqueza } \\
\text { cultural e a autenticidade não sejam perdidas }\end{array}$ \\
\hline \multirow[t]{2}{*}{ 10. Integridade Física } & 16. Implantação e design de novas estruturas de todos os tipos \\
\hline & 17. Boa manutenção de espações abertos e a redução de lixo \\
\hline 11. Diversidade Biológica & $\begin{array}{l}\text { 18. Gestão para a conservação e para a manutenção do turismo } \\
\text { enquanto atividade geradora de renda para a conservação }\end{array}$ \\
\hline 12. Eficiência de recursos & $\begin{array}{l}\text { 19. Encorajar formas de turismo e gestão de sistemas que são } \\
\text { eficientes, promovendo fontes de alternativas e incentivando a } \\
\text { redução, reutilização e reciclagem }\end{array}$ \\
\hline 13. Pureza ambiental & $\begin{array}{l}\text { 20. Promoção de formas menos poluentes de transportes e } \\
\text { minimizar e controlar as descargas de esgoto em ambientes } \\
\text { sensíveis }\end{array}$ \\
\hline 14. Sustentabilidade & $\begin{array}{l}\text { 21. Investimentos diretos ou indiretos no desenvolvimento do } \\
\text { turismo e de estratégias para a gestão ambiental }\end{array}$ \\
\hline $\begin{array}{l}\text { 15. Política Internacional } \\
\text { de boa vontade e paz }\end{array}$ & 22. Busca e cultura da paz \\
\hline
\end{tabular}

Fonte: Adaptado de Scott (2011).

É possível identificar que dentre os 15 objetivos identificados por Scott (2011), três deles são: eficiência de recursos, pureza ambiental e sustentabilidade, demonstrando que as políticas públicas turismo também podem possuir objetivos voltados à questão ambiental. Para Henz e Anjos (2014) as políticas de turismo precisam criar critérios que contemplem questões sociais e ambientais, tornando-se defensoras das localidades turísticas, mediando assim os interesses e as necessidades das localidades.

Nesta linha, recentemente, teóricos têm voltado seus estudos para o conceito de sustentabilidade, seguindo a tendência mundial, incluindo definições de desenvolvimento turístico sustentável que estão direcionadas a uma visão mais holística da realidade, valorizando questões ambientais (Tulik, 2003, Beni, 1999, Hall, 2004; Barretto, 2005; Ruschmann, 2010). Contudo, considerando a multidimensionalidade do conceito de desenvolvimento, é também importante considerar a formulação de políticas públicas que priorizem o desenvolvimento sus- 
tentável onde criem critérios de voltados a questões sociais e ambientais (Henz \& Anjos, 2014).

Segundo Bezerra (2003, p.53) desenvolvimento sustentável é "um processo que permite o desenvolvimento sem degradar ou esgotar os recursos que o tornam possível".Desta forma, desenvolvimento turístico com sustentabilidade considera os benefícios para anfitriões e visitantes, enquanto protege e melhora os recursos disponíveis para o futuro. Ruschmann (2010) afirma que a instalação e utilização de equipamentos e serviços para o atendimento do turismo de massa provocam inúmeros efeitos negativos sobre o meio ambiente. Tais impactos estão ligados as numerosas modificações, ou à sequência de eventos, provenientes do processo desenvolvimento turístico nas localidades receptoras.

A partir disso, pode-se considerar que o desenvolvimento turístico com sustentabilidade seria "aquele que atende às necessidades dos turistas atuais, sem comprometer a possibilidade do usufruto dos recursos pelas gerações futuras" (Bezerra, 2003, p.53). Segundo Oliveira, Minasse e Marques (2016) essa forma de desenvolvimento do turismo pode ser vista como uma oportunidade de se favorecer o desenvolvimento socioeconômico das localidades, bem como a preservação do meio ambiente como também a inclusão social.

Neste sentido, um dos objetivos perseguidos nas políticas públicas de turismo contemporâneas é justamente a sustentabilidade, definida pela OMT (2003) nos seguintes termos:

0 desenvolvimento do turismo sustentável atende às necessidades dos turistas de hoje e das regiões receptoras, ao mesmo tempo em que protege e amplia oportunidades para o futuro. É visto como um condutor de gerenciamento de todos os recursos, de tal forma que as necessidades econômicas, sociais e estéticas possam ser satisfeitas, sem desprezar a manutenção da integridade cultural, dos processos ecológicos essenciais, da diversidade biológica e dos sistemas que garantem a vida (OMT, 2003, p. 24).

Ainda, a Lei Geral do Turismo do Brasil (Art. 4ํ․ Parágrafo único da Lei n.ํㅜ 11.771/08, de 17 de setembro de 2008)estabelece como princípio para a Política Nacional de Turismo que:

A Política Nacional de Turismo obedecerá aos princípios constitucionais da livre iniciativa, da descentralização, da regionalização e do desenvolvimento econômico-social justo e sustentável.

Neste mesmo sentido, o Plano Nacional de Turismo (2013-2016), principal instrumento de referência para a política pública de turismo no Brasil, dentro de suas diretrizes tem como perspectiva "um desenvolvimento econômico sustentável, ambientalmente equilibrado e socialmente inclusivo e oferece a oportunidade e o desafio para a execução de ações capazes de equilibrar proteção ao meio ambiente ao seu uso economicamente sustentável" (Ministério do Turismo, 2013, p.52), visando o respeito aos costumes regionais, a inclusão social e a distribuição das riquezas. E uma de suas ações é "Estimular o Desenvolvimento Sustentável da Atividade Turística" (Ministério do Turismo, 2013, p.98). 
O entendimento de desenvolvimento turístico neste artigo está relacionado a destinos turísticos. Assim, A noção adotada para destino turístico é o de um local, normalmente uma cidade, onde o visitante pernoita e encontra condições para se hospedar e experimentar a gastronomia, bem como realizar atividades recreativas que possam ser feitas em um dia. 0 destino turístico possui limites físicos e administrativos que definem a sua gestão, imagens e percepções que determinam sua competitividade no mercado (OMT, 2005). Observa-se nesta noção que destino turístico é um território (país, região, estado, cidade) que recebe turistas (Hall, 2004), onde o mesmo deve ser visto e entendido como um produto turístico (Cooper, Fletcher, Fyall, Gilbert, Wanhill, 2007; Wallingre, 2009).

Dessa forma, torna-se necessário planejar o turismo de uma maneira que respeite a cultura já estabelecida e o meio ambiente da localidade que exerce a atividade turística, além de se prever a utilização de uma forma adequada e correta do ambiente natural e social das localidades. Somado a isso, o atrativo turístico deve ser pensado e planejado observando os aspectos socioambientais em sua totalidade, extrapolando essa análise ao seu entorno, visando com essas ações maximizar as potencialidades mercadológicas do local, garantindo a viabilidade econômica do empreendimento (Oliveira; Minasse; Marques, 2016).

Deste modo, pode-se considerar a questão ambiental no bojo das discussões sobre sustentabilidade como elemento significativo para compreensão na mensuração do desempenho turístico, ou seja, como um dos parâmetros de análise existentes e no consequente aperfeiçoamento da atividade turística, o que perpassa também pela necessidade de incorporação de tais inovações na formulação e implementação das políticas públicas de turismo.

Para fins deste trabalho, observa-se que a questão ambiental tem sido mencionada na atualidade em objetivos de política públicas e em ações de governos nacional (como o Brasil) e supranacionais como a OMT. Assim, considera-se a questão ambiental um aspecto relevante, pois pode comprometer a própria continuidade no desenvolvimento do turismo nos destinos. Todavia, como esta e outras questões estão sendo contempladas empiricamente em políticas públicas de turismo em governos subnacionais?

\section{MÉTODOS}

Para a realização do estudo empírico, optou-se pela abordagem qualitativa que por meio do método documental buscou-se analisar a política pública de turismo de um governo subnacional. A coleta e a análise dos dados foram realizadas com base no trabalho de Scott (2011) que apresenta um esquema analítico com 15 objetivos das políticas públicas de turismo e 22 formas de atuação do governo no setor turístico. Este esquema analítico foi aplicado na etapa/fase de tomada de decisão do ciclo de política pública, momento que, segundo Secchi (2013), é possível verificar nos marcos regulatórios que direcionam os governos os objetivos e ações planejadas para lidar com determinado problema ou setor público, neste caso, o turismo.

Desta forma, escolheu-se como destino turístico o estado de São Paulo no Brasil (Figura 1) para ser o lócus empírico deste estudo que por meio da sua administração pública do seu governo subnacional criou uma política pública estadual 
(nos últimos 5 anos) para orientar a focalização e a descentralização de recursos para o desenvolvimento turístico regional e local, que contempla inovações tanto na definição de municípios como sendo de "interesse turístico" ou como "cidade estância”, quanto das condições para a manutenção desta condição ao longo do tempo (Araújo, 2016, p.66). Este país foi escolhido por ser um caso sui generis no mundo por ser atualmente o único país federativo com uma organização trina de entes governamentais (união - governo federal; estados - governos estaduais; e municípios - governos municipais). Apesar de existirem estudos sobre políticas públicas de turismo em governos subnacionais no Brasil, com destaque para estudos sobre Minas Gerais (Emmendoerfer, Tomazzoni, Pimentel, 2014; Silva \& Passador, 2016), pesquisas sobre este objeto e com ênfase na questão ambiental no estado de São Paulo, considerado o maior destino turístico brasileiro, ainda não foram publicadas pela comunidade científica da área em periódicos especializados.

Com a definição do lócus de estudo, iniciou-se a pesquisa documental com bases nas legislações do governo do estado de São Paulo para o turismo, especificamente: Lei Complementar 1.261/2015 que estabelece condições para a classificação dos municípios em Estância ou em Município de Interesse Turístico; Resolução ST-14/2016 que estabelece diretrizes para a elaboração do plano diretor de turismo municipal; e, o Projeto de Lei 1.369/2015 que dispõe sobre o Fundo de Melhoria dos Municípios Turísticos.

Os dados documentais também foram extraídos de portais da internet, projetos, relatórios técnicos, cartilhas e mapas disponíveis na internet de organizações públicas de âmbitos estadual (governo do estado de São Paulo), nacional (Ministério do Turismo) e internacional como a Organização Mundial do Turismo (OMT). Todos os documentos utilizados foram indicados nas referências no final deste trabalho.

Assim, os dados coletados foram cotejados com base na literatura especializada expressa na seção 2 deste trabalho e permitiu nas seções subsequentes apresentar a política pública em estudo, bem como sua configuração em termos de objetivos e formas de atuação do governo com base na Tabela 1 que sintetizada o trabalho de Scott (2011). Com isso foi também possível identificar e selecionar os dados que compuseram a Tabela 2na seção dos resultados que revelam os objetivos e formas de atuação do Governo do estado de São Paulo, em termo de prioridades e abrangência.

\section{O TURISMO COMO OBJETO DE INTERESSE PÚBLICO NO ESTADO DE SÃO PAULO}

O estado de São Paulo é uma das 27 unidades federativas do Brasil, situado na região sudeste deste país, conforme a Figura 1, com uma capital cujo município possui o mesmo nome.

O Anuário Estatístico de Turismo do Brasil indicou que o estado de São Paulo é representa a maior economia estadual do país, sendo a principal porta de entrada para turistas estrangeiros, com a entrada nos últimos dois anos de mais de 2,2 milhões de visitantes (Ministério do Turismo, 2016). 
Segundo o Instituto Brasileiro de Geografia e Estatística (IBGE, 2016) o estado de São Paulo contém 645 municípios, uma população estimada de 44.396 .484 pessoas e uma área de 248.222,362 km². Desses municípios, 300 são classificados como potenciais para o turismo, segundo o Governo do Estado (São Paulo, 2016).

Figura 1 - Mapa da localização do estado de São Paulo, Brasil.

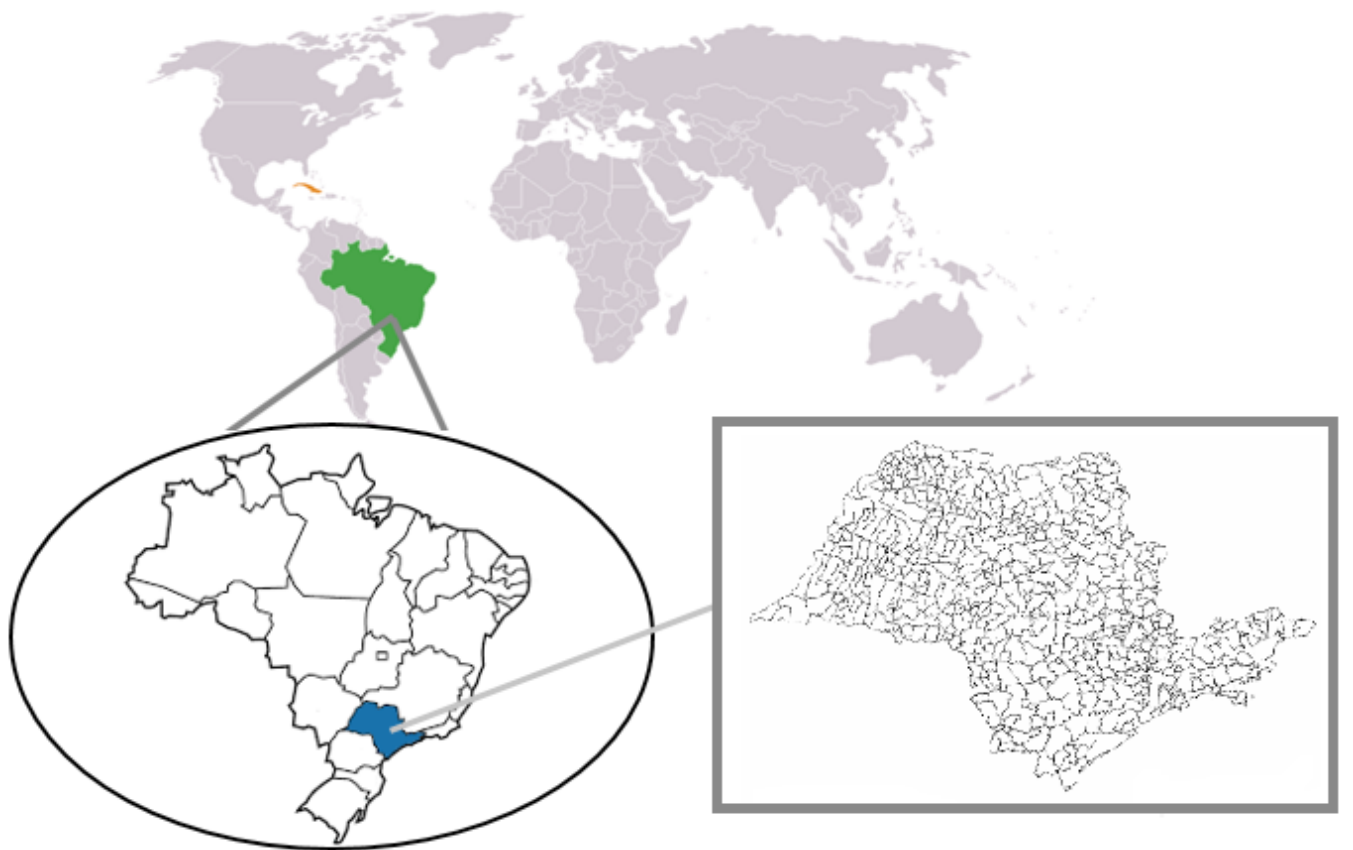

Fonte: Elaboração nossa.

No que se refere à atividade turística, o estado de São Paulo conta com 70 municípios classificados como Estâncias Turísticas e está divido em 15 macrorregiões turísticas, as quais se encontram subdividas em 34 regiões. Segundo o Governo de São Paulo o Estado foi dividido de tal maneira a fim de que o organizasse "... sob o ponto de vista de proximidade geográfica e semelhanças entre os produtos turísticos" (São Paulo, 2016).

O Estado de São Paulo, segundo Brocchi e Solha (2008), foi um dos primeiros estados brasileiros a implementar em sua estrutura administrativa um órgão de turismo. Tal fato aconteceu em 1965, com a criação da Secretaria de Negócios de Turismo. Com o decorrer dos anos a secretaria passou por diversas reformas administrativas e atualmente é denominada Secretaria de Turismo, através do decreto 56.635/2011 que dispões sobre as alterações de denominação e organização da Administração direta do Estado de São Paulo. De acordo com as autoras, tais mudanças constantes e descontínuas dos órgãos públicos de turismo revelam a pouca prioridade e fragilidade do setor, dificultando a continuidade de projetos consistentes e de longo prazo (Brocchi \& Solha, 2008).

Durante a década de 1980, o Estado de São Paulo voltou suas ações para o turismo social e de lazer. Já em 1990, o governo do estado se preocupou com a capacitação e formação dos profissionais do setor turístico, desenvolvendo ações para estes (Brocchi \& Solha, 2008)

Atualmente, o governo do Estado de São Paulo tem voltado seus esforços para o investimento e fomento da atividade turística em seu território. Ao total, são 7 
programas e ações listados pela Secretaria de Turismo do Estado de São Paulo (2017) cujos nomes e objetivos são:

- Melhor viagem: objetiva viabilizar aos grupos de terceira idade (acima de 60 anos) a realização de viagens aos destinos turísticos do Estado;

- Roda São Paulo: busca oferecer um passeio de ônibus a atrativos turísticos do Estado;

- Turismo do Saber: visa proporcionar uma nova experiência às crianças de escolas públicas do Estado, levando-as a ter um contato com diferentes culturas e paisagens;

- Caminha São Paulo: consiste em rotas contemplativas que permitem o turismo ir a pé ou de bicicleta em cidades com potenciais turísticos naturais e monumentais;

- Festival Gastronômico Sabor de São Paulo: busca dar destaque às criações culinárias dos municípios paulistas; e

- Municípios de Interesse Turístico e Estâncias Turísticas: busca destinar recursos à municípios já contemplados com o título de estância turística e à municípios com potenciais turísticos classificados como de interesse turístico.

Pode-se notar através de suas ações que o turismo no Estado de São Paulo tem sido investido e possui um grande potencial para gerar uma gama de benefícios para os destinos turísticos e para os municípios em seu entorno, através de seus atrativos turísticos em seus diversos segmentos (turismo de negócios, turismo de sol e praia, turismo de aventura, patrimônio histórico, saúde, além de outros).

A fim de estimular ainda mais a atividade turística dentro do Estado, dando aos municípios a oportunidade de desenvolverem seus potenciais turísticos, o governo do estado criou um Projeto de Lei Complementar (PLC 32/2012) o qual, posteriormente, deu origem a Lei Complementar no 1.261, de 29 de abril de 2015 - que tem como objetivo estabelecer "condições e requisitos para a classificação de Estâncias e de Municípios de Interesse Turístico [...]" (São Paulo, 2015).

Além de estabelecer as condições mínimas para a classificação dos municípios, a Lei Complementar 1.261/2015 gera ainda 140 novas vagas para que os municípios do estado possam concorrer ao título de Municípios de Interesse Turístico e dá a eles o direito de receber parte da verba disponibilizada pelo Fundo de Melhoria dos Municípios Turísticos, além de outros benefícios.

\section{ESTÂNCIAS TURÍSTICAS E MUNICÍPIOS DE INTERESSE TURÍSTICO NO ESTADO DE SÃO PAULO}

As Estâncias Turísticas são destinos consolidados que possuem um ou mais atrativos turísticos e que, devido a esses atrativos, mantêm um fluxo permanente de visitantes. Além disso, as Estâncias dispõem de uma infraestrutura composta de equipamentos e serviços turísticos que possibilitam o fácil acesso do turista ao atrativo que ele procura. Assim, pode ser definida como:

[...] Localidades beneficiadas por recursos naturais, paisagísticos, medicinais, históricos, artísticos, dentre outros, e que podem gerar um fluxo de turistas, estes, caracterizados pela longa permanência na localidade (Fino, 2009, p.48). 
Segundo a Secretaria de Turismo do Estado de São Paulo, atualmente, são considerados como Estâncias Turísticas 70 municípios, como pode se ver na Figura 2.É a partir da definição de Estância Turística que se pode explorar o título de Município de Interesse Turístico, criado em 2015, a partir da aprovação da Lei Complementar 1.261/2015 neste governo subnacional no Brasil.

Figura 2 - Estâncias turísticas no estado de São Paulo.

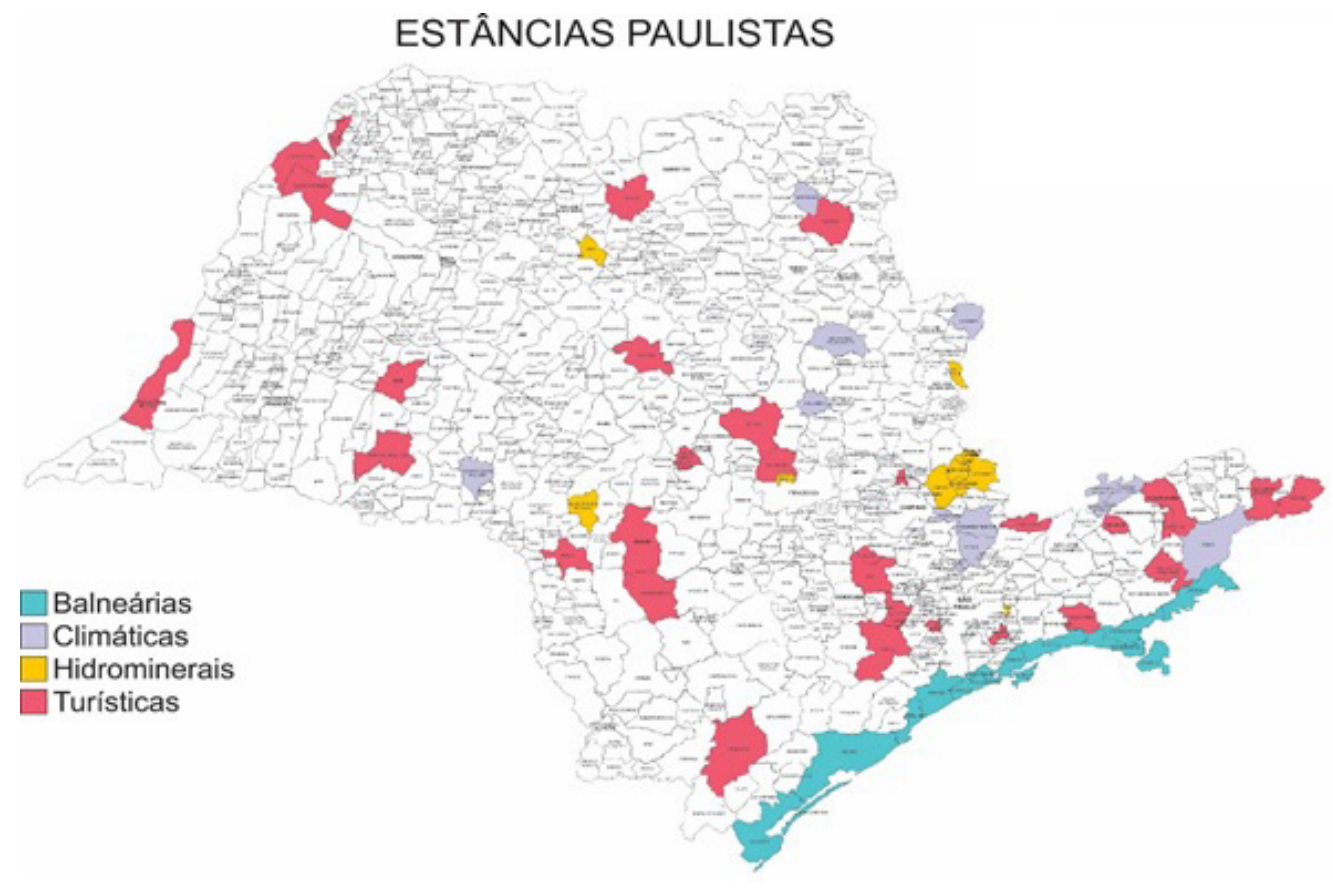

Fonte: São Paulo (2016).

O Município de Interesse Turístico é um título concedido à 140 municípios que, embora não sejam desenvolvidos e consolidados como as Estâncias Turísticas, possuem "expressivos atrativos turísticos de uso público e caráter permanente, naturais, culturais ou artificiais" (São Paulo,2015) e dispõem de uma infraestrutura básica para que a atividade turística aconteça.

À vista disso, entende-se que a classificação de Município de Interesse Turístico, proposta pela Lei 1.261/2015, é uma ação do Governo do Estado de São Paulo que oferece aos municípios com potencial turístico oportunidades para que eles se desenvolvam no setor de turismo.

Para concorrer ao título, a Lei 1.261/2015, define que os Municípios de Interesse Turístico, bem como as Estâncias, devem ter seus atrativos turísticos enquadrados em um, ou mais, dos 13 segmentos listados em seu texto. Além disso, para concorrer ao título, o município interessado deve ao mínimo ser um potencial turístico, dispor de equipamentos e serviços como alimentação, acesso a informações turísticas, meios de hospedagem na região e de infraestrutura básica como abastecimento de água e coleta de resíduos sólidos. 0 município também deverá ter um Conselho Municipal de Turismo ativo e possuir um plano diretor de turismo atualizado, seguindo as normas estabelecidas pela resolução ST-14, de 21 de junho de 2016.

A partir disso, se enquadrado a tais critérios, o município, representado por um deputado, deverá dispor de documentos como a demanda do ano anterior ao ano da candidatura, inventário contendo os equipamentos e serviços turísticos 
disponibilizados no município, plano diretor de turismo atualizado e as seis últimas atas do Conselho Municipal de Turismo- COMTUR.

\section{RESULTADOS}

Ao realizar a comparação entre a atuação dos Governos em várias partes do mundo com a atuação do Governo do Estado de São Paulo, pode-se observar que dos 15 objetivos identificados por Scott (2011), apenas 8 foram encontrados e que em relação as 22 atuações descritas pelo autor, apenas 9 foram identificadas na atuação do Governo em estudo, como pode ser visualizado na Tabela 2.

Tabela 2 - Objetivos e atuações identificadas na atuação do Governo de São Paulo

\begin{tabular}{|c|c|c|}
\hline $\begin{array}{c}\text { Objetivos das } \\
\text { Políticas Públicas } \\
\text { de Turismo } \\
\end{array}$ & $\begin{array}{l}\text { Atuação dos Governos em } \\
\text { Várias Partes do Mundo }\end{array}$ & $\begin{array}{l}\text { Atuação do Governo do Estado de } \\
\text { São Paulo }\end{array}$ \\
\hline $\begin{array}{l}\text { Desenvolvimento } \\
\text { Econômico }\end{array}$ & $\begin{array}{l}\text { Fortalecimento da imagem do } \\
\text { destino; }\end{array}$ & $\begin{array}{l}\text { Através dos títulos de Estância } \\
\text { Turística e Município de Interesse } \\
\text { Turístico reconhecido pelo Estado }\end{array}$ \\
\hline Competitividade & $\begin{array}{l}\text { Sistemas de qualidade e de } \\
\text { classificação obrigatórios } \\
\text { poderiam tornar-se voluntários e } \\
\text { ser colocados nas mãos do setor } \\
\text { privado ou terceiro setor. }\end{array}$ & $\begin{array}{l}\text { Estabelecimento de um } \\
\text { ranqueamento trianual para controle } \\
\text { por parte do Estado, previsto na Lei } \\
\text { Complementar de } 1.261 / 2016 .\end{array}$ \\
\hline \multirow[t]{2}{*}{ Prosperidade Local } & Criação de empregos em turismo & \multirow{2}{*}{$\begin{array}{l}\text { Destinação de verba para o } \\
\text { desenvolvimento das potencialidades } \\
\text { turísticas e infraestrutura dos } \\
\text { Municípios de Interesse Turístico, } \\
\text { resultando na promoção de } \\
\text { empregos. }\end{array}$} \\
\hline & $\begin{array}{l}\text { Contribuição para o } \\
\text { desenvolvimento de } \\
\text { infraestrutura. }\end{array}$ & \\
\hline $\begin{array}{l}\text { Bem-estar da } \\
\text { comunidade }\end{array}$ & $\begin{array}{l}\text { Realizar um planejamento } \\
\text { cuidadoso para garantir que } \\
\text { a comunidade local não sofra } \\
\text { com o turismo, como através do } \\
\text { congestionamento do tráfego, } \\
\text { barulho, comportamento } \\
\text { desrespeitoso, e competição por } \\
\text { recursos vitais, como a água. }\end{array}$ & $\begin{array}{l}\text { Criação de uma resolução (ST- } \\
\text { 14/2016) que estabelece condições } \\
\text { para a elaboração do plano diretor } \\
\text { de turismo nos municípios. }\end{array}$ \\
\hline Riqueza cultural & $\begin{array}{l}\text { Apoiar a conservação da cultura; } \\
\text { os sítios de patrimônio e } \\
\text { tradições históricos, controlando } \\
\text { o desenvolvimento do turismo } \\
\text { e o comportamento do visitante } \\
\text { para garantir que a riqueza } \\
\text { cultural e a autenticidade não } \\
\text { sejam perdidas. }\end{array}$ & $\begin{array}{l}\text { Identificado no artigo 2o, inciso } \\
\text { IV da resolução ST-14/2016, que } \\
\text { estabelece: "Considerar os aspectos } \\
\text { ambientais, culturais, sociais e } \\
\text { de preservação do patrimônio } \\
\text { material e imaterial e sua interação } \\
\text { sustentável com a atividade } \\
\text { turística". }\end{array}$ \\
\hline
\end{tabular}


Quadro 2 - Continuação

\begin{tabular}{|l|l|l|}
$\begin{array}{c}\text { Objetivos das } \\
\text { Políticas Públicas } \\
\text { de Turismo }\end{array}$ & \multicolumn{1}{|c|}{$\begin{array}{c}\text { Atuação dos Governos em } \\
\text { Várias Partes do Mundo }\end{array}$} & $\begin{array}{l}\text { Atuação do Governo do Estado de } \\
\text { São Paulo }\end{array}$ \\
\hline Integridade Física & $\begin{array}{l}\text { Boa manutenção de espações } \\
\text { abertos e a redução de lixo. }\end{array}$ & $\begin{array}{l}\text { Estabelecimento de uma norma } \\
\text { (Lei Complementar 1.261/2015, } \\
\text { capítulos II e III) que faz com que os } \\
\text { municípios de interesse turístico e as } \\
\text { estâncias turísticas disponham de no } \\
\text { mínimo uma estrutura de coleta de } \\
\text { resíduos sólidos. }\end{array}$ \\
\hline $\begin{array}{l}\text { Eficiência de } \\
\text { recursos }\end{array}$ & $\begin{array}{l}\text { Encorajar formas de turismo } \\
\text { e gestão de sistemas que são } \\
\text { eficientes, promovendo fontes } \\
\text { de alternativas e incentivando } \\
\text { a redução, reutilização e } \\
\text { reciclagem. }\end{array}$ & $\begin{array}{l}\text { Identificado no artigo 2o, inciso IV da } \\
\text { resolução ST-14, no que diz respeito } \\
\text { atividaderão sustentável com a }\end{array}$ \\
\hline $\begin{array}{l}\text { Investimentos diretos ou } \\
\text { indiretos no desenvolvimento do } \\
\text { turismo e de estratégias para a } \\
\text { gestão ambiental. }\end{array}$ & $\begin{array}{l}\text { Identificado na Lei 1.261/2015, } \\
\text { na proposta de investimento nos } \\
\text { municípios que se enquadram nos } \\
\text { requisitos. }\end{array}$ \\
\hline Sustentabilidade
\end{tabular}

Fonte: Elaboração própria com base em dados da pesquisa.

No que diz respeito à oferta de pesquisa e divulgação de informações sobre tendências futuras do mercado, não foi identificada nenhuma ação do Governo do Estado de São Paulo nos documentos consultados para análise. No entanto, quanto ao fortalecimento da imagem do destino, identifica-se uma atuação do Governo de São Paulo, uma vez que cria uma política pública de fomento à atividade turística e propicia aos municípios a oportunidade de adquirirem o título de Estância Turística ou o título de Município de Interesse Turístico. Assim, a partir da conquista do título, os municípios podem obter maior reconhecimento e maior atenção do Governo em relação aos demais municípios.

0 item de garantia ao acesso efetivo do mercado e prestação de consultoria, além do apoio aos negócios também não foi encontrado. Presume-se que a não oferta de uma previsão e indicação, por parte do Governo do Estado, pode ocasionar na dificuldade das organizações públicas e privadas, em nível local, de obterem um conhecimento comum mais aprofundado e de se relacionarem entre si. Isso pode resultar no não alinhamento dos objetivos esperados de cada município e na dificuldade de organização enquanto Município de Interesse Turístico ou enquanto Estância Turística.

A Lei 1.261/2015, em sua seção II, estabelece que a cada três anos o Poder Executivo deverá encaminhar à Assembleia Legislativa do Estado de São Paulo um Projeto de Lei Revisional dos Municípios Turísticos. O Projeto de Lei Revisional permitirá a criação de um ranking em que as três estâncias menos pontuadas perderão seu título e passarão a ser consideradas Municípios de Interesse Turístico, enquanto os três Municípios de Interesse Turístico mais bem classificados passarão a serem classificados como Estâncias Turísticas. Vale ressaltar que as Estâncias Turísticas que perderem seus títulos não poderão reconquistá-los. Presume-se que a criação do ranking propiciará numa constante manutenção dos 
atrativos turísticos por parte dos municípios, uma vez que é criado um ambiente competitivo no qual o município menos classificado perderá seu título e consequentemente seus benefícios.

No que concerne ao objetivo "qualidade de emprego", observou-se que apesar de buscar fomentar empregos para atender o mercado turístico não se observa nesta política uma preocupação com a profissionalização das organizações públicas para a gestão das políticas públicas de turismo.

Com relação ao atendimento ao visitante, no que se refere a proporcionar aos turistas uma experiência de viagem de qualidade, verificou-se que as estâncias já têm uma infraestrutura capaz de proporcionar isso, até mesmo por ser uma característica exigida por lei. No entanto, vê-se nos Municípios de Interesse Turístico uma limitação, uma vez que essa estrutura não é exigida a eles na lei 1.261/2015. Essa limitação se mostra tanto presencialmente, em pontos de informações e recepção de turísticas, quanto virtualmente, no oferecimento de sites e cartilhas de orientações aos turistas, mostrando seus principais atrativos turísticos, mapas, sugestões, dentre outras informações.

Embora seja exigido na Lei Complementar 1.261/2015 a presença de um Conselho Municipal de Turismo, garantindo aos municípios a oportunidade de decidirem sobre o desenvolvimento do turismo em suas localidades, ressalta-se que para garantir um empoderamento mais significativo dos residentes é necessário que se criem espaços e instrumentos de controle local mais deliberativos e acessíveis com perspectiva formativa de cidadãos conscientes para o desenvolvimento turístico com sustentabilidade. Este aspecto refere-se ao princípio da participação importante para a integração do federalismo (RUA; ROMANINI, 2013) onde há subgovernos nacionais como o estado de São Paulo que busca articular planos e ações de turismo articulados entre o estado e os municípios.

Observa-se que a política pública de turismo do Governo do Estado de São Paulo revela a preocupação com o bem-estar da comunidade uma vez que cria uma resolução (ST-14/2016) que estabelece condições para a elaboração do Plano Diretor de Turismo nos municípios para que não ocorra um sofrimento da comunidade local em decorrência da atividade turística. Todavia, somente o plano não garante este objetivo, tornando-se necessário requisitar marcos legais para que aconteça a proteção e o monitoramento dos fluxos de turista e dos empreendimentos para o turismo, de modo que a capacidade de carga do município não seja ultrapassada, gerando problemas sociais pontuais ou constantes.

Ainda no que se refere à resolução criada, observa-se que no artigo $2^{\circ}$ do inciso IV, prevê-se a consideração dos aspectos ambientais, culturais, sociais de preservação aos patrimônios dos municípios, no entanto, verificou-se uma limitação de indicar e esclarecer. Não se aprofunda nos mecanismos de apoio à conservação, apenas prevê uma consideração acerca do tema. Diante disso, é de se notar que a partir dessa lacuna abre-se ao Estado e aos Municípios uma oportunidade de se pensar em políticas integradas com a cultura e o patrimônio local, uma vez que se deve levar em consideração a abrangência e a intersetorialidade da atividade turística, conforme afirmam Beni (2003), Bezerra (2003) e Guedes (2003).

No que tange à boa manutenção de espaços abertos e redução de lixo, verifica-se que a política pública em estudo conta com mecanismos legais que estabelecem aos municípios de interesse turístico e às estâncias uma estrutura mínima de coleta de resíduos sólidos e manejo dos mesmos. No entanto, em relação à 
diversidade biológica e uso eficiente de recursos não se identifica na política pública aspectos que exploram sobre a fauna, flora, biodiversidade e unidades de conservação.

Diante disso, observa-se a importância do comprometimento das políticas públicas com os princípios do desenvolvimento sustentável para o alcance da integração de objetivos sociais, ambientais e econômicos, conforme afirma Hall (2000). Somado a isso, o argumento de Oliveira, Minasse e Marques (2016), se destaca ao afirmarem que um atrativo turístico deve ser pensado e planejado observando os aspectos socioambientais em sua totalidade, extrapolando essa análise ao seu entorno, o que não é totalmente visto na política analisada.

Desta forma, a análise dos dados revelou que a política pública de turismo no governo subnacional estudado não contempla as 15 ações e formas de atuar dos governos em outros países e lugares do mundo tratadas por Scott (2011). Observou-se no lócus estudado que há predominância na sustentabilidade econômica e baixa presença de ações públicas direcionadas a questão ambiental no setor turístico, denotando uma preocupação estatal periférica em relação a este aspecto. Uma evidência disso é a exigência inócua do Governo do Estado em requisitar algo existente e que não permite per si diferenciar os municípios candidatos ao MIT em relação a questão ambiental. A exigência estatal refere-se a coleta e tratamento de resíduos sólidos, cujos serviços de saneamento básico já são oferecidos pelo próprio Governo Estadual que atende todos os 645 municípios do Estado, segundo dados disponibilizados em 2008 pelo IBGE (2016), último ano em que foi elaborado o estudo acerca do tema.

Infere-se neste estudo que a falta de uma visão sustentável ou de detalhes que preconizam questões ambientais e sociais na política pública do Governo de São Paulo se dê pelo fato de a política pública se encontrar ainda no estágio de implementação do ciclo das políticas públicas.

O estágio de implementação, segundo Secchi (2013) é aquele que sucede a etapa da tomada de decisão e antecede a etapa de avaliação. 0 autor destaca que a importância de se estudar as definições oriundas da fase de tomada de decisão é uma oportunidade de visualizar a proposta de alcance e os limites presentes na política pública, que vão impactar naquilo que a população residente irá perceber e valorar. Além disso, esse autor ainda afirma que estudar o resultado da fase de tomada de decisão ajuda a "detectar problemas mal formulados, objetivos mal traçados, otimismos exagerados". Verifica-se a partir disso que aspectos que podem ser clarificados e aperfeiçoados na política pública do Governo do Estado de São Paulo, principalmente no que diz respeito à questão ambiental. E tal questão associada a multidimensionalidade da sustentabilidade poderia ser mais central na política pública de turismo no território e no governo subnacional estudado se incorporasse ações relacionada a educação ambiental e patrimonial, instrumentos de controle do fluxo diário de turistas para o monitoramento das poluições sonoras, visuais e do ar.

Somado a isso, observou-se também que a legislação analisada se focaliza principalmente nas condições para a classificação dos municípios em Estâncias Turísticas ou em Municípios de Interesse Turístico, porém dentre as condições estabelecidas na lei, a questão ambiental não é identificada de modo expressiva 
para fins de orientação e de estabelecimento de um desenvolvimento econômico, sustentável e social das localidades por meio do turismo.

A partir disso e sabendo que a política pública é voltada ao investimento por meio da verba disponibilizada pelo Fundo de Melhoria dos Municípios de Interesse Turístico, reforça-se aqui a ideia de que há a necessidade das políticas públicas de turismo incorporarem a noção de sustentabilidade de uma forma mais ampla, para além da dimensão econômica, para que a dimensão ambiental seja também tratada de modo equitativo. Isso possibilitaria se aproximar de princípios, diretrizes e objetivos que versam importantes instrumentos nacionais (Plano e Política Nacional de Turismo), assim como pautam ações promovidas e difundidas internacionalmente pela Organização das Nações Unidas (ONU) e pelo órgão mundial do setor (OMT).

\section{CONSIDERAÇões FInAIS}

A contribuição deste estudo foi demonstrar que a proposta e a abrangência de uma política pública de turismo, principalmente em termos de intencionalidade e direcionamento, podem ser analisadas por meio de tipos de objetivos e de formas de atuação de um governoem um determinado território considerado destino turístico. Esta análise permite também observar as prioridades e as questões consideradas importantes em uma política pública de turismo em países federativos como o Brasil, bem como revelar esforços do Estado em buscar ser mais inclusivo e integrador no tratamento de questões importantes como a ambiental por meio da política pública de turismo.

Ressalta-se que a presença plena de todos os objetivos e formas de atuação do governo tratados por Scott (2011) precisam ser observados pelos analistas em políticas públicas de turismo como uma forma ideal de concebê-los, o que requer reflexões sobre o potencial e alcance de sua proposta, bem como de sua apropriação em diferentes contextos subnacionais, como foi o esforço empreendido nesta pesquisa no estado de São Paulo. Assim, o uso da abordagem de Scott (2011) pode se revelar de modo diferente em governos subnacionais como em outros estados e, principalmente, em municípios, que possuem singularidades ambientais e na capacidade institucional do governo em intervir no setor turístico. Desta forma, observou-se que determinados objetivos de política pública de turismo de governos nacionais, como aqueles identificados por Scott (2011) podem não ser pertinentes para governos subnacionais, bem como diferentes em perspectiva comparada. Somado a isso, aqueles objetivos e formas de atuação não identificados no estudo sobre o estado de São Paulo, não denota necessariamente a ausência deles, porque isso pode depender dos métodos de pesquisa empregados.

Neste sentido, uma das limitações desta pesquisa foi o uso exclusivo do método documental, o que permitiu observar a realidade escolhida de forma parcial, cuja análise da política pública foi baseada em aspectos normativos e legais, a luz da literatura especializada. Entende-se que estudos futuros poderiam avançar em relação a isso ao envolverem outras fontes de pesquisa com técnicas como entrevistas in loco, questionários ou mesmo a análise documental da execução financeira do Estado. Ressalta-se que no momento da pesquisa, a política analisada encontrava-se na transição das fases tomada de decisão e implementação 
(Secchi, 2013), o que não impede realizar estudos sobre fases ou etapas anteriores como a formação da agenda, a fim de compreender o processo político de inserção e priorização de determinados temas e questões na agenda de políticas públicas (Kingdon, 2003).

Neste trabalho a questão ambiental foi identificada como sendo uma dimensão ainda periférica na política pública de turismo. Isso é algo que surpreende se for levado em consideração os argumentos da literatura especializada, que consideram que esta questão é uma das que mais sofrem impactos negativos por causa da atividade turística. Neste sentido, entende-se que para um município ser de fato considerado de interesse turístico, não somente pela definição de uma política pública, os diferentes entes governamentais de um país necessitam fomentar e promover condições mais amplas e diversificadas para que o centro das atenções englobe questões essenciais que estão na periferia das prioridades governamentais no contexto do turismo, como a questão ambiental discutida neste estudo.

Assim, este estudo também chama a atenção da necessidade de se resgatar a centralidade de questões como a ambiental, ou de modo mais amplo, da sustentabilidade. Especialmente como essas questões têm sido mencionadas e efetivadas em políticas públicas de turismo, que tem no ambiente natural e construído uma de suas bases principais para atrair e estimular fluxos periódicos de turistas, de modo saudável e satisfatório para os residentes e para aqueles que trabalham direto e indiretamente nesta nos municípios.

A descentralização de recursos que um contexto federalista como o Brasil exige que governos subnacionais estaduais repassem recursos para os municípios terem capacidade institucional de desenvolverem a atividade turística, uma vez que os mecanismos de arrecadação de recursos financeiros em nível municipal são limitados e dependentes dos governos federal e estadual. Porém, objetivos e ações públicas induzidas por meio de políticas públicas de turismo podem fomentar projetos intersetoriais onde a questão ambiental pode ser articulada com educação e saúde para um ambiente de qualidade que favoreça o destino tanto para o residente quanto para o turista.

Portanto, o tema federalismo indicado neste trabalho pode servir de ponto de partida para novas empreitadas intelectuais nos estudos de turismo relacionados a gestão e políticas públicas, induzindo a geração de novas pesquisas e da formação de uma agenda de investigação em rede e em perspectiva comparada envolvendo outros governos subnacionais, em nível estadual no Brasil, e em nível municipal com outros países federativos.

Em termos empíricos, a que se pensar em práticas de conscientização e formação de servidores, de gestores públicos a respeito do tema "sustentabilidade" aplicada a políticas públicas de turismo, bem como a proposição e validação de indicadores para acompanhar e monitorar o desempenho dos objetivos e formas de atuação governamental, em parceria ou não com a sociedade.

\section{REFERÊNCIAS}

Airey, D. (2015). Developments in understanding tourism policy. Tourism Review,70(4), 246-258. 
Alvarez, M. D., \& Cooper, C. (2014). Tourism as an Instrument for Development: A Theoretical and Practical Study. Bradford: EmeraldGroupPublishing.

Araujo, C. M. (2016). Novos Rumos para o Turismo do Estado de São Paulo: do Projeto de Lei Complementar 32/2012 à Aprovação da Lei Complementar N. 32/2015. Anais Brasileiros de Estudos Turísticos-ABET, 6(1), 58-71.

Barreto, M.(2003). 0 imprescindível aporte das Ciências Sociais para o planejamento e a compreensão do turismo. Horizontes Antropológicos, 9(20),15-29.

Beni, M. C. (2003). Dimensão e Dinâmica de Clusters no Desenvolvimento Sustentável do Turismo. In Bahl, M. Turismo: enfoques teóricos e práticos (pp.35-45).São Paulo: Roca.

Beni, M. C.(1999).Política e estratégia do desenvolvimento regional: planejamento integrado e sustentável do turismo. Revista Turismo em Análise, 10(1), 7-17.

Berry, S. \&Ladkin, A.(1997). Sustainabletourism: a regional perspective. Tourism Management, 18(7), 433-440.

Bezerra, D. (2003). Programa Nacional de Municipalização do Turismo: Análise de uma Política Pública em Desenvolvimento. In Bahl, M. Turismo: enfoques teóricos e práti$\cos ($ pp. 47-67). São Paulo: Roca.

Borges, G. \& Passador, J. (2016). Redistribuição fiscal para o desenvolvimento turístico local e regional. Revista de Administração Pública, 50(4), 587-610.

Brasil. (2008). Lei no 11.771/08 de 17 de setembro de 2008. Dispõe sobre a Política Nacional de Turismo, define as atribuições do Governo Federal no planejamento, desenvolvimento e estímulo ao setor turístico; revoga a Lei no 6.505, de 13 de dezembro de 1977, o Decreto-Lei no 2.294, de 21 de novembro de 1986, e dispositivos da Lei no 8.181, de 28 de março de 1991; e dá outras providências. Recuperado em 10 dezembro de 2016, de http://www.planalto.gov.br/ccivil_03/_ato2007-2010/2008/lei/111771.htm.

Brocchi, R. \& Solha, K. (2008). Institucionalização do turismo no poder público estadual: a experiência de São Paulo. Revista Turismo em Análise, 19(2). Recuperado em https:// www.revistas.usp.br/rta/article/view/14152.

Carvalho, A. (2000). Políticas Públicas em Turismo no Brasil. Revista Sociedade e Cultu$r a, 3(1 / 2), 97-109$.

Cooper, C., Fletcher, J., Fyall, A., Gilbert, D. \&Wanhill, S. (2007). Turismo, Princípios e Prática(3a ed.). São Paulo: Bookman.

Dwyer, L., \&Spurr, R. (2012). Tourism Economics Summary. STCRC Centre for Economics and Policy.

Emmendoerfer, M.L., Tomazzoni, E.L. \& Pimentel, T.D. (2014). In: Pimentel, T. D., Emmendoerfer, M. L. \&Tomazzoni, E. L. (Orgs.). Gestão Pública do Turismo no Brasil: Teorias, Metodologias e Aplicações. Caxias do Sul, RS: EDUCS.

Feitosa, M. \& Gómez, C. (2013) Aplicação do TourismEcologicalFootprintMethod para avaliação dos impactos ambientais do turismo em ilhas: um estudo em Fernando de Noronha. Revista Brasileira de Pesquisa em Turismo, 7(2), 220-238.

Fino, P. (2009).Estância Turística de Salto - SP: Turismo por Decreto (Dissertação de Mestrado). Universidade de Araraquara, São Paulo, SP, Brasil.

ForumofFederations. (2016). Annual Reports and Evaluations. Ottawa: FoF, 2016. Recuperado em http://www.forumfed.org/.

Goeldner, C., Ritchie E, J., \& Robert M. (2002). Turismo: princípios, práticas e filosofias (8a ed.).Porto Alegre: Bookman.

Guedes, L. C. (2003). O problema na Sociedade Pós-industrial. InBahl, M. Perspectivas do Turismo na Sociedade Pós-industrial (pp.47-67).São Paulo: Roca. 
Hall, C. M. (2004) Planejamento turístico(2a ed). São Paulo: Contexto.

Hall, C. M. (2000). Tourism planning: Policies, processes and relationships. Harlow: Pearson Education.

Henz, A. P \& Anjos, F. A. (2014). A construção de políticas de turismo no Brasil: abordagens sobre Estado, governo, políticas públicas e descentralização. In Anais do Seminário da Associação Nacional de Pesquisa e Pós-Graduação em Turismo, Fortaleza, CE, Brasil, 11. Recuperado em 12 de novembro, 2016 de http://www.anptur.org.br/novo_portal/anais_anptur/anais_ 2014/arquivos/DTP/DTP1/094.pdf Instituto Brasileiro de Geografia e Estatística - IBGE (2016). Estados@. Recuperado em 16 de março, 2016 de www.ibge.gov.br/estadosat/perfil.php?sigla=sp\#

Jacobi, P. (2003, março). Educação ambiental, cidadania e sustentabilidade. Cadernos de Pesquisa, 118, 189-205.

Jafari, J. (1994). La cientifización del turismo. Estudios y Perspectivas en Turismo. 3(1), 7-36.

Kingdon, J. (2003). Agendas, Alternatives, and Public Policies. 3.ed. New York: Harper Collins.

Knupp, M. E. C. G. (2015). Fundamentos do Turismo. Curitiba: InterSaberes.

Lima, G. F. C. (1999). Questão ambiental e educação: contribuições para o debate. Ambiente \& Sociedade,Ano II, (5), 135-153.

Lopes, A. O. B.,Tinôco, D. S. \& Souza, L. M. (2011). Avaliação de Políticas Públicas de Turismo: uma análise bibliométrica dos periódicos de turismo. Turismo em Análise, 22(3), 614-631. Recuperado em 9 de junho, 2016 de DOI: 10.11606/issn.1984-4867. v22i3p614-631

Ministério do Turismo. (2013). Plano Nacional de Turismo 2013-2016. Brasília: Recuperado em 10 dezembro de 2016, de: http://www.turismo.gov.br/images/pdf/plano_nacional_2013.pdf.

Ministério do Turismo. (2016). Anuário estatístico de turismo 2016. Recuperado em 10 dezembro de 2016, de http://www.dadosefatos.turismo.gov.br/2016-02-04-11-53-05/ item/download/440_268262d9bdef3912cbdea85a0599e997.html.

Oliveira, C. S., Minasse, M. H. G. \& Marques, S. C. M (2015). Processo de Formatação de Atrativos Turísticos Sustentáveis. Revista Turismo em Análise.26(3). Recuperado em 9 de junho, 2016 de DOI: 10.11606/issn.1984-4867.v26i3p639-667

Organização Mundial do Turismo - OMT (2003). Guia de desenvolvimento do turismo sustentável. São Paulo: Bookman.

Pimentel, T.D., Pimentel, M.P.C. \& Vidal, J.P. (2017). Políticas públicas de turismo numa perspectiva normativa comparada: os casos de Brasil e Espanha. Revista de Turismo y Patrimonio Cultural, 15(2), 293-310.

Rua, M. G. \&Romanni, R. (2013). Unidade XI - Federalismo e Descentralização das Políticas Públicas no Brasil: Organização e Funcionamento dos Sistemas e Programas Nacionais: Sistema Único de Saúde (SUS) e Sistema Único de Assistência Social (SUAS). In Rua, M. G.,Romanni, R. (Orgs). Para Aprender Políticas Públicas. Instituto de Gestão, Economia e Políticas Públicas (IGEPP). Recuperado em 9 de maio, 2016, de http://igepp.com.br/ uploads/ebook/ unidade_xi.pdf

Ruschmann, D. (2010).Turismo e Planejamento Sustentável: A Proteção do Meio Ambiente(16a ed). São Paulo: Papirus.

São Paulo (estado). (2015). Lei Complementar no 1.261, de 29 de abril de 2015. Estabelece condições e requisitos para a classificação de Estâncias e de Municípios de Interesse Turístico e dá providências correlatas. Diário Oficial [do] Estado de São Paulo. São Paulo, 
SP, 30 abr. 2015. Recuperado em 5 de dezembro, 2016, de http://www.al.sp.gov.br/repositorio/legislacao/lei.complementar/2015/lei.complementar-1261-29.04.2015.html

São Paulo (estado). (2017).Secretaria de Turismo do Estado de São Paulo.Programas e Ações. Recuperado em 25 de outubro, 2017, de http://www.turismo.sp.gov.br/publico/ noticia_assunto_lista.php?cod_menu=39

São Paulo (estado). (2016).Secretaria de Turismo do Governo do Estado de São Paulo. Recuperado em 16 de dezembro, 2016, de http://turismo.sp.gov.br/

Scott, N. (2001). Tourism Policy: A Strategic Review.Oxford, Goodfellow. Recuperado em http://www.goodfellowpublishers.com/free_files/ fileTourismPolicy.pdf

Secchi, L. (2013). Políticas Públicas: Conceitos, Esquemas de Análise, Casos Práticos (2a ed.). São Paulo: Cengage Learning.

Solha, K.T. (2004).Órgãos públicos estaduais e o desenvolvimento do turismo no Brasil. Tese de Doutorado). Universidade de São Paulo, São Paulo, SP, Brasil.

Torres, A-D. \&Palomeque, F. (2014). Measuring sustainable tourism at the municipal level. AnnalsofTourismResearch, 49, 122-137.

Tulik, O. (1993). Recursos naturais e turismo: tendências contemporâneas. Revista Turismo em Análise, 4(2), pp. 26-36. Recuperado deDOI: 10.11606/issn.1984-4867. v10i1p7-17

Wallingre, N. (2009). La definición de productos en los destinos turísticos. InWallingre, N; Villar, A. Desarrollo y gestión de destinos turísticos.Bernal: Universidad Nacional de Quilmes, pp. 183-203.

Young, E. A. (2015)Federalism as a Constitutional Principle. University of Cincinnati Law Review, 83, 1057.

Recebido em: 16/12/2016

Aprovado em: 10/11/2017

\section{Contribuição}

Cynthia Oliveira de Souza: Revisão de literatura; Coleta e análise de dados; Redação DO ARTIGO; FoRMATAÇÃo.

Magnus Luiz Emmendoerfer: ELABORAÇÃo dE RESUMO, ABSTRACT E RESUMEN; REVISÃo DE LITERATURA; ANÁLISE dos RESUlTAdos E CONSIDERAções FINAIS; REVISÃo TEXTUAL E FORMATAÇ̃̃o.

Marcos Eduardo Carvalho Gonçalves Knupp: REvisÃo dE LITERATURA; ANÁLISE doS RESULTADOS; Conclusão; REVISÃo teXTUAL E FORMATAÇ̃̃o. 